\title{
WETLANDS CONSTRUÍDOS COM MEIO SUPORTE DE SOLO NA REMOÇÃO DE COLIFORMES TERMOTOLERANTES DE ESGOTOS DOMÉSTICOS
}

\author{
WETLANDS CONSTRUCTED WITH SOIL SUPPORT MEDIUM IN REMOVAL OF \\ THERMOTOLERANT COLIFORMS FROM DOMESTIC SEWAGE
}

Selma Cristina Silvaa , Maria Lucrécia Gerosa Ramos ${ }^{b}$, Ricardo Silveira Bernardesc

${ }^{a}$ Centro de Ciências Exatas e Tecnológicas da UFRB, ${ }^{b}$ Faculdade de Agronomia e Medicina Veterinária da Universidade de Brasília,

${ }^{c}$ Faculdade de Tecnologia/Departamento de Engenharia Civil-UnB

scsilva00@yahoo.com.br, lucrecia@unb.br, rsilveirabernardes@gmail.com

Submissão: 10 de janeiro de 2020 Aceitação: 08 de dezembro de 2020

\section{Resumo}

O trabalho avaliou o desempenho dos wetlands construídos de fluxo vertical (WCFV) com meio suporte de solo misturado com areia na remoção de coliformes termotolerantes (CTer). O experimento era composto por dois sistemas: 1. Monocultura: Latossolo vermelho-amarelo plantado com a cultura do arroz (Oriza sativa L), operado com diferente taxa de aplicação de hidráulica (TAH) de esgoto de $4 \mathrm{~cm} / \mathrm{d}, 8 \mathrm{~cm} / \mathrm{d}$ e 15 $\mathrm{cm} / \mathrm{d}$; 2. Policultura: Latossolo amarelo plantado com as culturas do arroz (Oriza sativa L), do feijão (Phaseolus vulgaris $\mathrm{L}$ ) e do milho (Zea mays), operado com TAH de $2,4 \mathrm{~cm} / \mathrm{d}$ e $4,7 \mathrm{~cm} / \mathrm{d}$. As eficiências de remoção de CTer variaram, respectivamente, de $87,8 \%$ a $100 \%$ e $97,8 \%$ a $100 \%$ nos sistemas 1 e 2 . Os fatores que contribuíram para a remoção de CTer foram a baixa umidade, o baixo teor de matéria orgânica e a colmatação. Os dois solos se mostraram eficientes na remoção de CTer. A rotação de culturas proporcionou uma remoção maior e em um período mais longo de tempo de operação, além de ter contribuído para um maior controle a colmatação do solo. Independentemente do tipo de solo e dele estar sendo cultivado com monocultura ou policultura, nos primeiros cinco meses de operação dos sistemas (1 ${ }^{\circ}$ ciclo), as TAH mais baixa favoreceram uma maior remoção de CTer com maior variabilidade nas eficiências de remoção. Com a continuidade da aplicação do esgoto para tratamento (2ำ ciclo), as eficiências de remoção reduziram e se tornaram aproximadamente constantes, sendo maiores quando se utilizou maior $\mathrm{TAH}$.

Palavras chaves: condutividade hidráulica; águas residuárias; microrganismos patogênicos; colmatação, rotatividade de culturas.

\section{Abstract}

The work evaluated the performance of constructed wetlands vertical flow (WCFV) with soil support medium mixed with sand in the removal of thermotolerant coliforms (ThC). The experiment consisted of two systems: 1. Monoculture: Red-yellow Latosol planted with rice (Oriza sativa $L$ ), operated with hydraulic application rates (HAR) of $4 \mathrm{~cm} / \mathrm{d}, 8 \mathrm{~cm} / \mathrm{d}$ and $15.0 \mathrm{~cm} / \mathrm{d}$; 2. Polyculture: Yellow Latosol planted with rice (Oriza sativa $L$ ), beans (Phaseolus vulgaris $L$ ) and maize (Zea mays), operated with HAR of $2.4 \mathrm{~cm} / \mathrm{d}$ and $4.7 \mathrm{~cm} / \mathrm{d}$. ThC removal efficiencies ranged from 87.8 to $100 \%$ and 97.8 to $100 \%$, respectively, in systems 1 and 2 . The factors that contributed to the removal of ThC were low humidity, low organic matter and clogging. Both soils proved to be efficient in removing ThC. Crop rotation provided greater removal in a longer period of operation, in addition to controlling soil clogging. Regardless of the type of soil and whether it is being cultivated with monoculture or polyculture, in the first five months of operation of the systems (1st cycle), the lower HAR favored greater removal of ThC with greater variability in removal efficiency. With the continued application of sewage for treatment (2nd cycle), the removal efficiencies reduced and became approximately constant, being higher for the highest HAR.

Key words: hydraulic conductivity; wastewater; pathogenic microorganisms; clogging, crop rotation. 


\section{INTRODUÇÃO}

Os esgotos sanitários possuem elevada concentração de coliformes termotolerantes (CTer), da ordem de $10^{6}$ a $10^{9}$ UFC/100mL (VON SPERLING, 2014). A remoção desses microrganismos dos esgotos é realizada por processos químicos ou biológicos. Geralmente, em Estações de Tratamento de Esgotos (ETE) de médio e grande porte, a desinfeção é realizada por processos químicos à base de cloro ou ozônio. Nas ETE de pequeno porte, que atendem localidades com grande disponibilidade de área, são empregados os processos biológicos: lagoas de maturação e wetlands construídos. Estes têm como vantagem sobre aqueles: a produção de efluentes isentos de algas; a realização de tratamento secundário e terciário em um único tanque; a produção de biomassa vegetal, que poderá ser utilizada como ração animal e para a promoção do equilíbrio entre a retirada e as emissões de $\mathrm{CO}_{2}$ da atmosfera; a manutenção do paisagismo local, em caso da utilização de plantas ornamentais; evita a produção de odores; e, também, pode produzir grãos para serem consumidos ou comercializados pela comunidade local, quando a planta auxiliar no tratamento for uma cultura produtora de grãos de base alimentar humana.

Os wetlands construídos são filtros biológicos plantados desenvolvidos pelo homem que simulam os processos ecológicos encontrados nos ecossistemas naturais (zonas úmidas, várzeas, brejos, banhados ou zonas alagadiças) e representam uma inovação e solução emergente de proteção e recuperação ambiental nos países em desenvolvimento, que dispõem de grandes áreas para sua implantação (VYMAZAL, 2011). Esses sistemas têm sido estudados e utilizados para o tratamento de águas de baixa qualidade, inclusive residuárias, por várias décadas e têm apresentado eficiências satisfatórias na remoção de matéria orgânica, sólidos em suspensão, nutrientes e de microrganismos patogênicos. Porém, há uma grande variação nas eficiências de remoção de CTer, que são influenciada pelo tipo de planta (macrófitas), meio suporte/filtrante/substrato e forma de operação dos sistemas (AMORIM et al., 2019; ASSUNÇÃO et al., 2017; COLARES; SANDRI, 2013; ABOU-ELELA; HELLAL, 2012).

Os filtros biológicos plantados, quando projetados adequadamente, são capazes de reduzir significativamente as concentrações de microrganismos patogênicos presentes nas águas residuárias. Essa redução é influenciada por vários fatores, tais como: adsorção, tamanho dos grãos do meio poroso, taxa de aplicação hidráulica (TAH), colmatação, umidade, $\mathrm{pH}$, temperatura, teor de matéria orgânica, espécies bacterianas, predação e parasitismo (STEVIK et al., 2004). Pode ocorrer, ainda, oxidação, efeito biocida resultante dos exsudatos liberados por algumas macrófitas, retenção nas raízes das plantas e no biofilme, competição, morte natural ou por radiação solar (STEFANAKIS; AKRATOS, 2016).

Em wetlands construídos que utilizam solos estéreis como meio suporte/filtrante, os microrganismos e as raízes das plantas são os principais responsáveis pela remoção de microrganismos patogênicos que são adicionados ao solo via aplicação do esgoto para tratamento (CAVINATTO; PAGANINI, 2007). Entre os microrganismos presentes no solo, as bactérias fluorescentes dos gêneros Pseudomonas e Bacillus spp são os mais abundantes e considerados importantes agentes no controle biológico, uma vez que podem eliminar os microrganismos patogênicos na rizosfera (FORTES NETO et al., 2017).

Os microrganismos podem ser removidos após percolação dos esgotos no meio poroso em um tempo relativamente curto, e o processo de colmatação pode contribuir para a sua eliminação por meio de retenção e de adsorção (STEVIK et al., 2004). Contudo, a colmatação física ou biológica, pode levar a um decréscimo da condutividade hidráulica $(K)$ dos wetlands construídos, reduzindo tanto a vazão efluente como a eficiência de remoção dos poluentes (MATOS et al., 2015).

A colmatação física é geralmente atribuída à fixação de material suspenso ou coloidal nos poros do solo. Segundo Blazejewski e MuratBlazejewska (1997), esse tipo de colmatação também ocorre devido a géis inorgânicos, principalmente de dissolução de cálcio $(\mathrm{Ca})$ de material calcário; peptização dos colóides do solo; colapso de macroporos entre os agregados, além da precipitação e deposição de carbonato de cálcio $\left(\mathrm{CaCO}_{3}\right)$ em baixos valores de $\mathrm{pH}$. Para $\mathrm{Fu}$ et al. (2013), a colmatação pode ser atribuída principalmente à matéria orgânica lábil (fração particulada) ou ativa e ao ácido fúlvico, com o primeiro desempenhando o papel mais importante no processo.

A colmatação biológica ou microbiana ocorre pelo acúmulo de bactérias e pela produção de 
exopolissacarídeos. Geralmente, o grau de colmatação tem correlação com o número de bactérias no perfil do solo, e alguns estudos têm mostrado que as células bacterianas podem reduzir drasticamente a $K$ de um meio poroso (MAGESAN et al., 2000), principalmente nos solos microporosos.

Nos solos macroporosos, a colmatação pode ser melhor controlada, uma vez que o movimento dos gases é mais rápido e mantém uma maior aeração em comparação aos solos microporosos (HORN; SMUCKER, 2005), que apresentam partículas finas não agregadas e não uniformes (BLAZEJEWSKI; MURATBLAZEJEWSKA, 1997).

Com o progresso da colmatação, e consequente redução da $\mathrm{K}$ do solo, o fluxo é dificultado e o esgoto escoa por caminhos preferenciais e, quando a colmatação está em estágio mais avançado, provoca, inclusive, o escoamento superficial acima do nível do leito filtrante (MATOS et al., 2018). Esse é um problema recorrente em wetlands construídos e pode ser minimizado por meio do controle de sólidos e das cargas hidráulicas e orgânicas aplicadas (TREIN et al., 2015).

Diante do exposto, este trabalho teve como objetivo avaliar o desempenho dos wetlands construídos de fluxo vertical com meio suporte de dois solos (Latossolo Vermelho-Amarelo e Latossolo-Amarelo) modificados, operados com diferentes taxas de aplicação hidráulica (TAH) de esgotos, na remoção de coliformes temotolerantes (Cter) e no controle da colmatação, em sistemas de monocultura e policultura.

\section{METODOLOGIA}

Foram utilizados dois tipos de solos como meio suporte dos Wetlands Construídos: o Latossolo Vermelho-Amarelo e o Latossolo Amarelo. O primeiro foi plantado com a cultura do arroz, em sistema de monocultura, enquanto o segundo com as culturas do arroz, do feijão e do milho, fazendo rotatividade entre estas, em sistema de policultura. Um desenho esquemático do estudo pode ser observado na Figura 1.

No sistema 1, com monocultura de arroz (Oriza sativa L.), as unidades experimentais eram representadas por bombonas plásticas cilíndricas (tambores) com capacidade de 200L, altura de $0,87 \mathrm{~m}$, diâmetro interno de $0,60 \mathrm{~m}$ e área superficial de $0,26 \mathrm{~m}^{2}$. Esse sistema era composto por 18 unidades experimentais. Em cada conjunto de 6 (seis) unidades, 3 (três) plantadas (wetlands construídos - WCFV) e 3 (três) sem planta (controles - CTR), foram utilizadas diferentes TAH $(4,8$ e $15 \mathrm{~cm} / \mathrm{d})$. No sistema 2, com policultura de arroz (Oriza sativa L.), feijão (Phaseolus vulgaris L.) e milho (Zea mays), as unidades experimentais eram de caixas d'água plásticas com capacidade de 100 litros, altura de 0,41m, diâmetro interno de $0,73 \mathrm{~m}$ e área superficial de $0,42 m^{2}$. Esse sistema também possuía 18 unidades experimentais e, em cada conjunto de 9 (nove), foi aplicada uma TAH (2,4 e 4,8 cm/d).

As unidades dos dois sistemas eram providas de mangueiras medidoras de nível para medir as perdas de cargas dos solos antes e após o final dos ciclos de operação.

As tubulações de drenagem dos dois sistemas eram de PVC de 40mm de diâmetro, perfuradas com orifícios de $1 \mathrm{~cm}$, espaçados a $2,5 \mathrm{~cm}$ e envolvidas com bidim. Sobre as tubulações de drenagem foram colocadas $10 \mathrm{~cm}$ de brita $\mathrm{n}^{\circ}$ 1, uma tela de malha fina e uma pequena camada de areia com diferentes granulometrias em ordem decrescente de diâmetro. Em seguida, as unidades foram preenchidas com seus respectivos meios suportes (solos). No sistema 1, de monocultura, foi utilizado o solo (Latossolo Vermelho-Amarelo) misturado com areia média na proporção de 1,0:1,5 (solo:areia), o qual era composto por $2,7 \%$ de pedregulho médio, $12,4 \%$ de pedregulho fino, $15,3 \%$ de areia grossa, $31,6 \%$ de areia média, $29,8 \%$ de areia fina, $3,1 \%$ de silte e $5 \%$ de argila, o que garantiu uma $\mathrm{K} 10^{-3} \mathrm{~cm} / \mathrm{s}$. A espessura da camada filtrante era de $55 \mathrm{~cm}$. No sistema 2, de policultura, o Latossolo Amarelo foi misturado com areia grossa na proporção de 1,00:1,75 (solo:areia) e era caracterizado como arenoso, uma vez que possuía 86,35\% de areia, 7,65 de silte e $7 \%$ de argila, o que proporcionou uma $\mathrm{K}$ de $10^{-2} \mathrm{~cm} / \mathrm{s}$. A espessura da camada filtrante foi de $20 \mathrm{~cm}$.

No sistema 1, o arroz (Oryza sativa L.) foi semeado em um canteiro em solo previamente adubado. A germinação ocorreu aos 9 (nove) dias após a semeadura e, após 25 (vinte e cinco) dias, as mudas foram transplantadas para as unidades de wetlands construídos. No sistema 2, as mudas foram produzidas em sacos plásticos e transplantadas 7 (sete) dias após a germinação. Todas as unidades experimentais foram plantadas com a cultura do arroz e, a partir do segundo ciclo, cada conjunto de 3 (três) unidades 
recebeu um tipo de cultura (arroz, feijão e milho). A parti do terceiro ciclo, iniciou a rotatividade entre as culturas.

Nos dois sistemas (1. monocultura e 2 . Polucultura), foi aplicado o esgoto primário para tratamento. A alimentação das unidades experimentais ocorreu de forma intermitente, por fluxo vertical, nas segundas, quartas e sextasfeiras. Nos outros dias, as unidades ficavam em descanso para aeração dos solos, necessária tanto à nitrificação do efluente como ao controle da colmatação dos solos. O sistema 1 foi operado por (dez) 10 meses (dois ciclos da cultura do arroz), enquanto o sistema 2, por 24 meses (cinco ciclos da cultura do arroz).

A qualidade dos esgotos afluentes e efluentes foi analisada com base nos procedimentos do manual "Standard Methods for Examination of Water and Wastewater" (APHAAWWA-WPCF, 1985).

\section{Figura 1: Resumo esquemático dos sistemas experimentais}

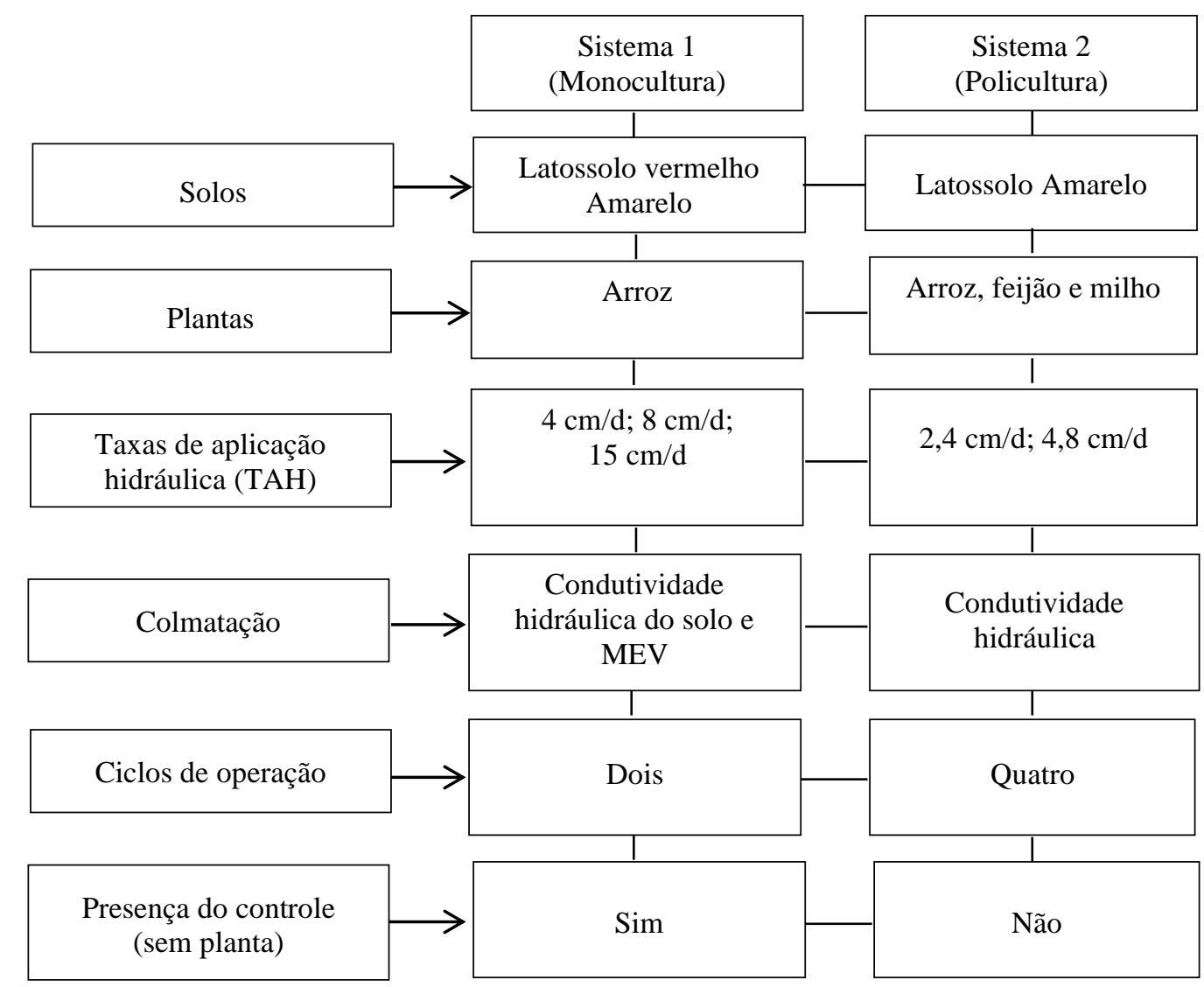

Fonte: Os autores

\subsection{Remoção de CTer}

Para a avaliação do desempenho dos WCFV e CTR na remoção de Cter, foram coletadas, quinzenalmente, amostras simples dos afluentes e efluentes produzidos por cada unidade experimental. A determinação do número mais provável (NMP/100mL) de CTer foi realizada pela técnica de fermentação de tubos múltiplos, em duas fases: a presuntiva e a confirmatória, conforme Silva et al. (2010). Das diluições seriadas na prova presuntiva, alíquotas de $1 \mathrm{~mL}$ foram inoculadas em Caldo Lauril Sulfato Triptose (LST) contendo tubos de Durhan invertidos e incubados durante 24 a $48 \mathrm{~h}$ a $35 \pm 1^{\circ} \mathrm{C}$. A positividade do teste foi verificada por meio da formação de gás nos tubos de Durhan e turvação do meio. Um inóculo dos tubos positivos foi transferido para tubos de $10 \mathrm{~mL}$ contendo caldo Eschericia coli (EC) e incubados a $45^{\circ} \mathrm{C}$ em banho-maria por $24 \mathrm{~h}$, com tubos de Durham invertidos. A positividade da prova foi verificada de forma idêntica à da prova presuntiva. Anotaram-se os resultados positivos de cada série, para posterior consulta à tabela de Hoskins adaptada pelo Bacteriological Analytical Manual BAM (1984). Para a observação da presença de E. coli, os tubos positivos de EC foram semeados em meio Agar Eosina Azul de Metileno (EMB) e incubados a $35^{\circ} \mathrm{C}$ por $24 \mathrm{~h}$. As colônias 
características de E. coli, isto é, com diâmetro de 2 a $5 \mathrm{~mm}$, centro negro, com ou sem brilho metálico esverdeado, foram isoladas em tubos de ensaio contendo Agar Triptona Soja (TSA) e incubados a $35^{\circ} \mathrm{C}$ por $24 \mathrm{~h}$.

\subsection{Colmatação do meio suporte (solo)}

A colmatação do solo foi avaliada por meio do cálculo da perda de carga, observando alterações na $K$ dos solos. No sistema de monocultura, também, empregou-se a técnica de Microscopia Eletrônica de Varredura (MEV) para visualizar a formação do biofilme nas partículas dos solos e das raízes das plantas.

\section{- Condutividade hidráulica do solo (K)}

A $\mathrm{K}$ foi medida a partir da equação de Darcy (Eq.1).

$$
Q=K A \frac{\left(h_{1}-h_{2}\right)}{L}
$$

Onde:

Q - vazão constante que passa pelo unidade experimental $\left(L^{3 / T}\right)$;

$\mathrm{K}$ - condutividade hidráulica ( $\mathrm{L} / \mathrm{T})$;

A - área da seção transversal do tambor $\left(\mathrm{L}^{2}\right)$;

$\mathrm{h}_{1}$ e $\mathrm{h}_{2}$ - carga hidráulica nos piezômetros 1 e 2 (m);

$\mathrm{L}$ - distância que a água percorre no meio

suporte entre os piezômetros 1 e 2 (m).

As perdas de cargas foram medidas observando-se as diferenças entre os níveis de água nos referidos piezômetros nos solos previamente saturados.

\section{Microscopia Eletrônica de Varredura (MEV)}

A formação do biofilme nas amostras coletadas, nas camadas de $0-5 \mathrm{~cm}$ dos solos e nas raízes antes e após a aplicação dos esgotos para tratamento, foi observada por meio da técnica de MEV, de acordo com os procedimentos descritos por Alberts et al. (1997).

A preparação das amostras de solos e das raízes para a MEV foi realizada de acordo com o seguinte protocolo:

Fixação: Esta é uma das etapas mais importantes para a microscopia eletrônica, pois preserva a estrutura do tecido de maneira que as alterações provocadas pelas etapas posteriores (desidratação ao ponto crítico, metalização e bombardeamento com feixe de elétrons) sejam minimizadas. A fixação é realizada com a solução de Karnovisky (mistura de 2\% glutaraldeído, 2\% paraformaldeído e $3 \%$ de sacarose em uma solução tampão de cacodilato de sódio a 0,05M).

Desidratação: Este procedimento foi necessário para retirar toda a umidade da amostra, porque o equipamento trabalha sob vácuo e a presença da água pode danificá-lo. A desidratação das amostras de solos foi feita com sílica, e a das raízes com acetona.

As amostras de solo foram montadas sobre suportes metálicos (stubs) e colocadas junto com a sílica em placas de petri de vidro tampadas por um período de $24 \mathrm{~h}$ para absorver a umidade.

As amostras das raízes foram desidratadas em concentrações de 30\%, 50\%, 70\% e 100\% de acetona (P.A. - A.C.S. $\left.\left(\mathrm{CH}_{3}\right)_{2} \mathrm{CO}\right)$, por 15 minutos em cada concentração.

As amostras de solo foram desidratadas ao ponto crítico, que se refere a certas condições de temperatura, às quais devem ser submetidas, para que suas fases líquida e gasosa coexistam. No equilamento de ponto crítico modelo CDD 030 (Balzers), a acetona líquida é substituída por $\mathrm{CO}_{2}$ em seu estado líquido (temperatura entre $3 \stackrel{\circ}{\mathrm{C}}$ e 4 oC). A secagem ao ponto crítico ocorre pela simples passagem do $\mathrm{CO}_{2}$ do estado líquido para o gasoso, sem a formação de tensão superficial e, portanto, sem provocar deformações no material. Após a desidratação ao ponto crítico, as amostras foram montadas nos suportes metálicos (stubs) e levadas ao MEV.

Metalização: Essa etapa consiste em uma cobertura de superfície com ouro durante 60 segundos, num processo realizado no equipamento Sputter Coater Modelo SCD 050 (Balzers) para a eletrização das amostras.

Bombardeamento com feixes de elétrons: Após a preparação, as amostras foram levadas ao microscópio para observação e posterior fotografias.

\section{RESULTADOS}

\subsection{Sistema de monocultura}

\subsubsection{Influência da TAH e da planta do arroz na remoção de $C T e r$}

O comportamento dos wetlands construídos na remoção de CTer ao longo do período de operação dos sistemas pode ser observado na Figura 2. 


\section{Figura 2: Concentrações de CTer (NMP/100mL) nos afluentes e efluentes dos WCFV e CTR ao longo do período de operação}

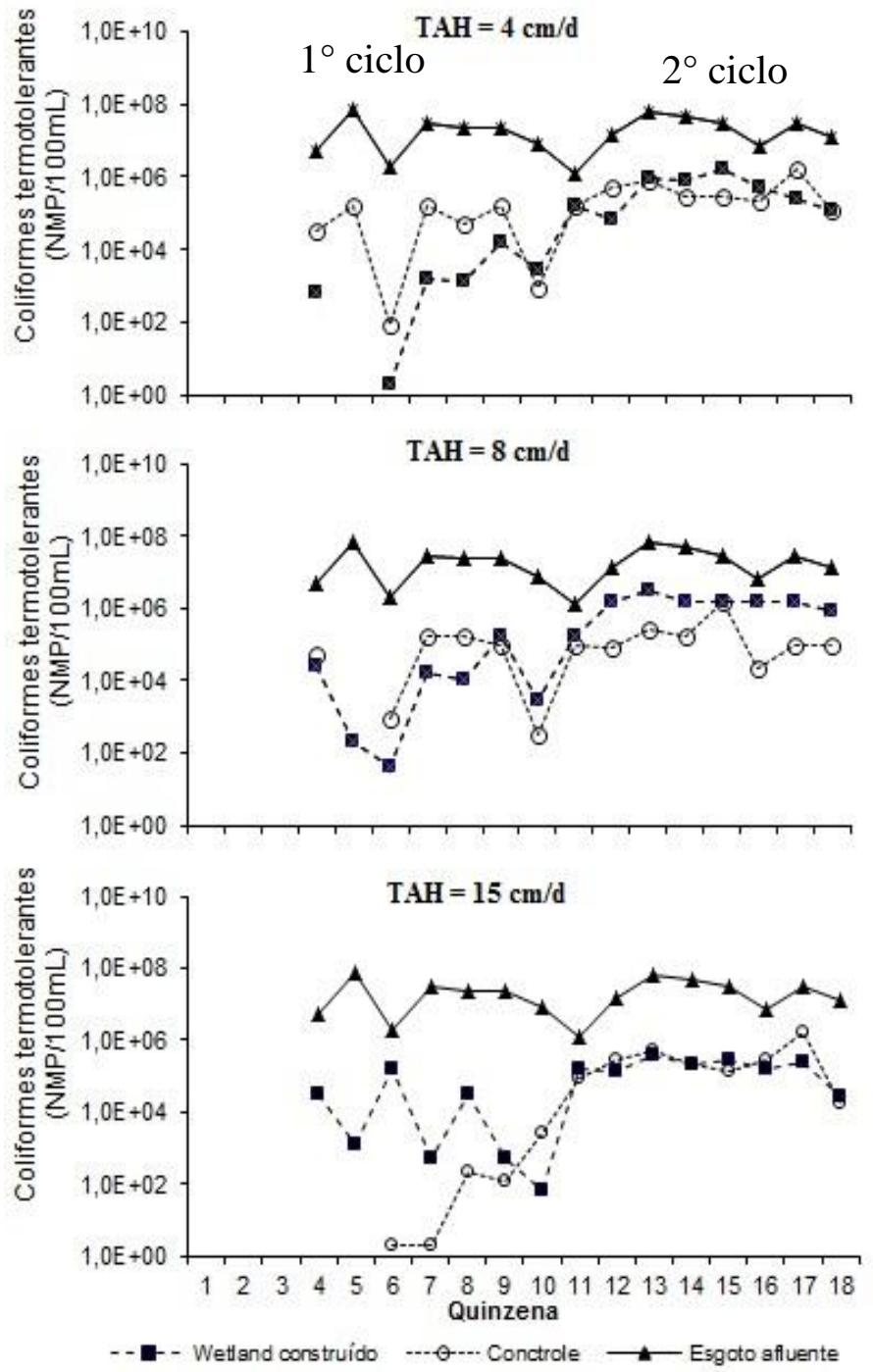

Fonte: Os autores.

Observa-se que o comportamento dos WCFV e dos CTR operados com TAH de 4, 8 e $15 \mathrm{~cm} / \mathrm{d}$, em geral, foi semelhante. No $1^{\circ}$ ciclo da cultura do arroz, houve uma maior oscilação da remoção de CTer, tendendo a ficar constante no $2^{\circ}$ ciclo, principalmente nos sistemas que receberam maiores $\mathrm{TAH}$, embora, em alguns períodos de avaliação tenham ocorrido picos de oscilação das concentrações nas unidades controles (Figura 2). Amorim et al. (2019) observaram que, após 110 dias de monitoramento, a remoção de CTer se tornou praticamente constante, porém sem eficiência adequada.

A concentração média de CTer no esgoto afluente era da ordem de $10^{7} \mathrm{NMP} / 100 \mathrm{~mL}$. Ao percolar pelos leitos filtrantes, quando detectada, variou de $10^{\circ}$ a $10^{6} \mathrm{NMP} / 100 \mathrm{~mL}$, ou seja, as concentrações foram reduzidas, respectivamente, de 6 para 1 ordem de grandeza. A grande variabilidade dos WCFV na remoção de CTer tem sido observada por vários autores (AMORIM et al., 2019; AVELAR; MATOS; MATOS, 2019; ANDREO-MARTÍNEZA et al., 2017).

No 1ํ ciclo do arroz, ao se aplicar TAH de 4 $\mathrm{cm} / \mathrm{d}$ nos WCFV, a redução de CTer foi significativamente maior $(p<0,05)$ quando comparados àqueles que receberam $\mathrm{TAH}$ de $8 \mathrm{~cm} / \mathrm{d}$ e $15 \mathrm{~cm} / \mathrm{d}$, não havendo diferença significativa entre essas. Os WCFV operados com $\mathrm{TAH}$ de $4 \mathrm{~cm} / \mathrm{d}$ removeram concentrações de CTer significativamente maiores $(p<0,05)$ que os CTR, e com a TAH de $15 \mathrm{~cm} / \mathrm{d}$, ocorreu o inverso. No $2^{\circ}$ ciclo, a variabilidade reduziu, e os WCFV operados com TAH de $15 \mathrm{~cm} / \mathrm{d}$ removeram quantidades significativamente $(p<0,05)$ maiores de CTer se comparados àqueles que receberam TAH de $8 \mathrm{~cm} / \mathrm{d}$. Não houve diferença significativa 
$(p<0,05)$ entre os WCFV operados com TAH de 4 e de $15 \mathrm{~cm} / \mathrm{d}$, embora, na maior parte do período, os sistemas operados com $15 \mathrm{~cm} / \mathrm{d}$ tenham removido maiores quantidades de CTer (Tabela 1).

Os WCFV operados com TAH de $15 \mathrm{~cm} / \mathrm{d}$ removeram quantidades de CTer significativamente $(p<0,05)$ superiores aos CTR alimentados com a mesma TAH, e estes removeram quantidades significativamente maiores quando a TAH foi de $8 \mathrm{~cm} / \mathrm{d}$. Com a TAH de $4 \mathrm{~cm} / \mathrm{d}$, não houve diferença significativa entre os tratamentos (WCFV e CTR).
Considerando todo o período de operação, os sistemas WCFV operados com TAH de 4 e 15 $\mathrm{cm} / \mathrm{d}$ apresentaram melhores remoções, não havendo diferença significativa entre eles, porém, as remoções foram significativamente $(p<0,05)$ maiores comparadas àqueles que receberem TAH de $8 \mathrm{~cm} / \mathrm{d}$. Nos CTR, embora as eficiências médias de remoção, obtidas com a TAH de 8 e 15 $\mathrm{cm} / \mathrm{d}$, tenham sido melhores, não houve diferença significativa entre as três TAH. Os CTR operados com $\mathrm{TAH}$ de $8 \mathrm{~cm} / \mathrm{d}$ removeram quantidades significativamente maiores $(p<0,05)$ de CTer se comparados aos WCFV (Tabela 1).

Tabela 1: Concentrações médias \pm desvio padrão $(\mathrm{NMP} / 100 \mathrm{~mL})$ de CTer afluentes e efluentes às unidades WCFV e CTR

\begin{tabular}{|c|c|c|c|c|}
\hline & \multicolumn{2}{|c|}{ 1 ciclo } & \multicolumn{2}{|c|}{$2^{\circ}$ ciclo } \\
\hline & WCFV & CTR & WCFV & CTR \\
\hline DP & \multicolumn{2}{|c|}{$20.287 .500 \pm 22.866 .159$} & \multicolumn{2}{|c|}{$29.714 .286 \pm 20.934 .137$} \\
\hline & $22.938 \pm$ & & & \\
\hline $4(\mathrm{~cm} / \mathrm{d})$ & $55.668 a A$ & $90.752 \pm 75.818 \mathrm{bB}$ & $\begin{array}{c}446.667 \pm 360.162 \mathrm{aA} \\
1.728 .571 \pm\end{array}$ & $550.000 \pm 512.803 \mathrm{aA}$ \\
\hline $8(\mathrm{~cm} / \mathrm{d})$ & $46.882 \pm 70.316 \mathrm{aB}$ & $68.901 \pm 67.530 \mathrm{aB}$ & $699.319 \mathrm{bB}$ & $328.857 \pm 656.310 \mathrm{aA}$ \\
\hline $\begin{array}{c}15 \\
(\mathrm{~cm} / \mathrm{d})\end{array}$ & $47.796 \pm 70.434 \mathrm{bB}$ & $11.645 \pm 31.675 \mathrm{aA}$ & $208.143 \pm 109.213 a A$ & $439.571 \pm 534.802 \mathrm{bA}$ \\
\hline \multicolumn{5}{|c|}{ Todo o período de operação } \\
\hline DP & \multicolumn{4}{|c|}{$24.686 .667 \pm 21.747 .278$} \\
\hline & \multicolumn{2}{|c|}{ WCFV } & \multicolumn{2}{|c|}{ CTR } \\
\hline $4(\mathrm{~cm} / \mathrm{d})$ & \multirow{2}{*}{\multicolumn{2}{|c|}{$\begin{array}{l}204.536 \pm 314.504 a A \\
831.671 \pm 982.964 b B\end{array}$}} & \multicolumn{2}{|c|}{$305.068 \pm 414.507 \mathrm{aA}$} \\
\hline $8(\mathrm{~cm} / \mathrm{d})$ & & & \multicolumn{2}{|c|}{$190.214 \pm 396.562 \mathrm{aA}$} \\
\hline $\begin{array}{c}15 \\
\text { (cm/d) }\end{array}$ & \multicolumn{2}{|c|}{$122.625 \pm 120.202 \mathrm{aA}$} & \multicolumn{2}{|c|}{$211.344 \pm 414.621 \mathrm{aA}$} \\
\hline
\end{tabular}

Letras minúsculas nas linhas comparam os tratamentos (wetlands construídos e controles) e as maiúsculas nas colunas compraram as TAH dentro do mesmo tratamento, ao nível de significância de $p<0,05$, pelo teste de Tukey. Fonte: Os autores.

As melhores remoções dos WCFV podem ser atribuídas à atuação das rizobactérias, por meio de predação, competição por espaço e nutrientes, produção de sideróforos, substâncias exsudadas pela rizosfera (FORTES NETO et al., 2017) e rápida ciclagem de nutrientes, uma vez que, em solos tratados com esgoto, a atividade microbiana é elevada (SILVA; BERNARDES; RAMOS, 2015), o que favorece a mineralização da matéria orgânica e, consequentemente, a redução dos CTer.

As maiores eficiências de remoção de CTer nos WCFV e CTR ocorreram durante o primeiro ciclo da cultura do arroz, variando, em grande parte, de 99,9 a 100\% (Tabela 2), com redução, respectivamente, de 3 a 7 casas logarítmicas.
Nota-se que, no $2^{\circ}$ ciclo da cultura do arroz, houve uma queda nas eficiências dos WCFV e dos CTR, e as remoções, em praticamente todo o período, variaram, respectivamente, de $92,8 \%$ a $99,8 \%$ e de $94,7 \%$ a $99,8 \%$ (Tabela 2 ). Tanto os WCFV como os CTR reduziram de 1 a 2 casas logarítmicas de CTer, porém, os WCVF operados com TAH de $15 \mathrm{~cm} / \mathrm{d}$ e os CRT com $8 \mathrm{~cm} / \mathrm{d}$ tiveram melhores desempenho na remoção desses microrganismos.

O menor desempenho dos WCFV e CTR, no $2^{\circ}$ ciclo, pode ser atribuído aos maiores teores de matéria orgânica e de umidade dos solos, pois foi observado por Abel et al. (2014) que solos com menor umidade remove maior quantidade de $E$. coli. À medida que os teores de matéria orgânica 
(MO) (Tabela 3) e a colmatação aumentaram, houve uma maior retenção de umidade nos solos, o que causou a redução da eficiência de remoção de CTer (Tabela 2). Andraus (2006) ressalta que, na década de 70 , os estudos já mostravam a influência do aumento dos teores de MO na sobrevivência de coliformes no solo, em função da sua capacidade de retenção de umidade.

Tabela 2: Eficiências médias quinzenais de remoções de CTer dos WCFV e CTR em dois ciclos da cultura do arroz, sob três TAH $(4,8$ e $15 \mathrm{~cm} / \mathrm{d})$

\begin{tabular}{|c|c|c|c|c|c|c|}
\hline \multirow[b]{2}{*}{ Quinzena } & \multicolumn{3}{|c|}{ WCFV } & \multicolumn{3}{|c|}{ CTR } \\
\hline & $4 \mathrm{~cm} / \mathrm{d}$ & $8 \mathrm{~cm} / \mathrm{d}$ & $15 \mathrm{~cm} / \mathrm{d}$ & $4 \mathrm{~cm} / \mathrm{d}$ & $8 \mathrm{~cm} / \mathrm{d}$ & $15 \mathrm{~cm} / \mathrm{d}$ \\
\hline & \multicolumn{6}{|c|}{$1^{\circ}$ ciclo } \\
\hline 4 & 99,9860 & 99,5200 & 99,4000 & 99,3000 & 99,0000 & 100,0000 \\
\hline 5 & 100,0000 & 99,9997 & 99,9981 & 99,7714 & 100,0000 & 100,0000 \\
\hline 6 & 99,9999 & 99,9980 & 92,0000 & 99,9955 & 99,9550 & 99,9999 \\
\hline 7 & 99,9943 & 99,9433 & 99,9983 & 99,4667 & 99,4667 & 100,0000 \\
\hline 8 & 99,9943 & 99,9522 & 99,8696 & 99,7826 & 99,3043 & 99,9990 \\
\hline 9 & 99,9261 & 99,3043 & 99,9978 & 99,3043 & 99,6087 & 99,9994 \\
\hline 10 & 99,9650 & 99,9650 & 99,9991 & 99,9884 & 99,9961 & 99,9650 \\
\hline \multirow[t]{2}{*}{11} & 87,6923 & 87,6923 & 87,6923 & 87,6923 & 93,0769 & 93,0769 \\
\hline & \multicolumn{6}{|c|}{$2^{\circ}$ ciclo } \\
\hline 12 & 99,5000 & 88,5714 & 99,0000 & 96,4286 & 99,4286 & 97,8571 \\
\hline 13 & 98,5859 & 95,0000 & 99,4375 & 98,7500 & 99,6094 & 99,1953 \\
\hline 14 & 98,3300 & 96,8000 & 99,5600 & 99,4000 & 99,6600 & 99,5700 \\
\hline 15 & 94,6667 & 94,6667 & 99,0000 & 99,0000 & 94,6667 & 99,5667 \\
\hline 16 & 92,8571 & 97,1429 & 97,5714 & 96,8571 & 99,6857 & 95,7143 \\
\hline 17 & 99,2000 & 94,6667 & 99,2000 & 94,6667 & 99,7000 & 94,6667 \\
\hline 18 & 99,0000 & 93,0769 & 99,7923 & 99,0000 & 99,3077 & 99,8692 \\
\hline
\end{tabular}

Fonte: Os autores.

Tabela 3: Matéria orgânica remanescente ( $\mathrm{g} \mathrm{MO} / \mathrm{kg}$ de solo) na camada de $0-5 \mathrm{~cm}$ dos solos dos WCFV e CTR, após o $1^{\circ}$ e o $2^{\circ}$ ciclos da cultura do arroz (SILVA; RAMOS; BERMNARDES, 2015)

\begin{tabular}{|c|c|c|c|c|c|c|}
\hline \multirow{3}{*}{$\mathrm{TAH}(\mathrm{cm} / \mathrm{d})$} & \multirow{2}{*}{\multicolumn{2}{|c|}{$\begin{array}{l}1 \% \text { ciclo } \\
0-5 \mathrm{~cm}\end{array}$}} & \multicolumn{4}{|c|}{$2^{\circ}$ ciclo } \\
\hline & & & $0-5$ & & $5-20 \mathrm{~cm}$ & \\
\hline & WCFV & CTR & WCFV & CTR & WCFV & CTR \\
\hline 4 & 5,20 & 3,27 & 14,03 & 11,30 & 10,93 & $\begin{array}{c}11.3 \\
0\end{array}$ \\
\hline 8 & 6,47 & 6,63 & 14,83 & 11,43 & 12,67 & $\begin{array}{c}11,4 \\
3\end{array}$ \\
\hline 15 & 7,20 & 7,07 & 17,67 & 13,20 & 12,10 & $\begin{array}{c}13,2 \\
0\end{array}$ \\
\hline
\end{tabular}

TAH - Taxa de aplicação hidráulica do esgoto; WCFV - Wetlands Construídos de Fluxo Vertical; CTR - Controle. Fonte: Os autores.

No $1^{\text {o }}$ ciclo, as maiores remoções de CTer nos WCFV ocorreram quando se aplicou a TAH de $4 \mathrm{~cm} / \mathrm{d}$, apesar de $25 \%$ dos resultados apresentarem maior NMP/100 mL, e o uso de taxas maiores (8 e $15 \mathrm{~cm} / \mathrm{d}$ ) causou uma maior variabilidade. A melhor eficiência de filtros operados com baixas TAH de esgoto comparados aos de altas taxas, na remoção de CTer, também foi observada por Ausland et al. (2002). No $2^{\circ}$ ciclo, as maiores remoções ocorreram quando se aplicou a taxa de $15 \mathrm{~cm} / \mathrm{d}$, tendo uma ótima representatividade, pouca variabilidade e ótima assimetria (Figura 3). 
Figura 3: Gráfico boxplot da remoção de CTer pelas unidades WCFV, considerando as diferentes TAH

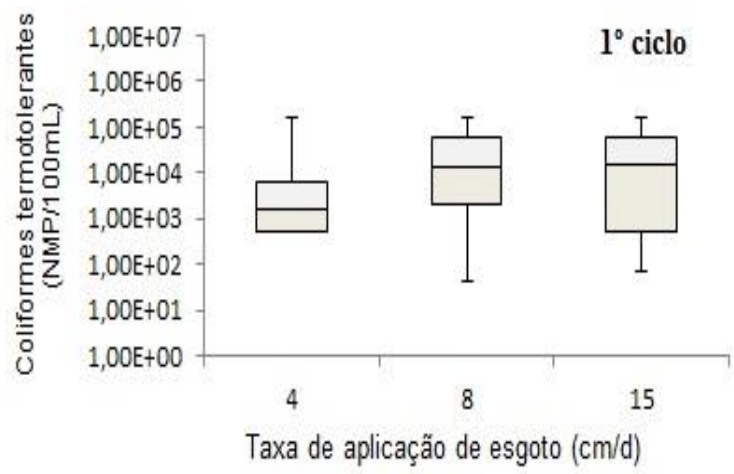

Fonte: Os autores.

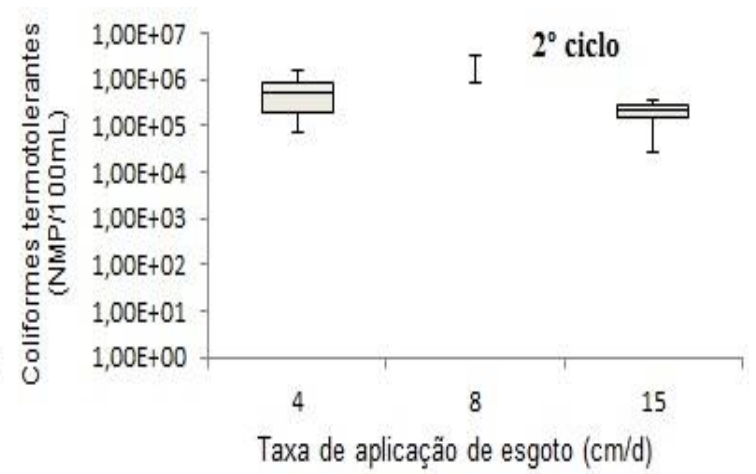

foi maior quando utilizada uma TAH de $8 \mathrm{~cm} / \mathrm{d}$, embora de $15 \mathrm{~cm} / \mathrm{d}$ tenha apresentado melhor simetria e menor variabilidade (Figura 4).

maior TAH $(15 \mathrm{~cm} / \mathrm{d})$ proporcionou uma maior remoção de CTer, com pouca variabilidade e ótima assimetria. No $2^{\circ}$ ciclo, a remoção de CTer

Figura 4: Gráfico boxplot da remoção de CTer pelas unidades CTR, considerando as diferentes TAH

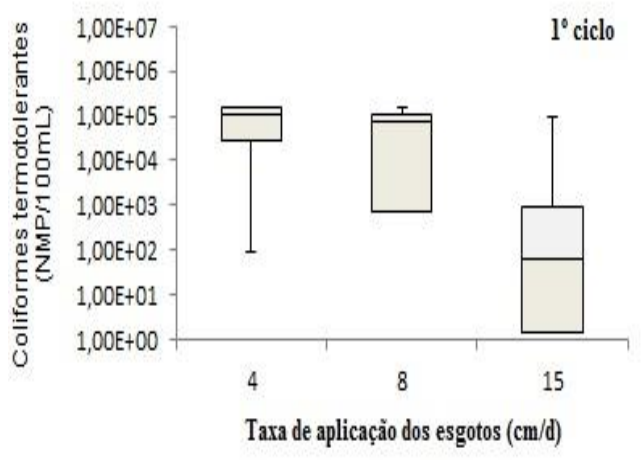

Fonte: Os autores.

A variabilidade na remoção de CTer em wetlands construídos tem sido observada por diferentes autores, independente do tipo de meio suporte, plantas ou forma de operação (Tabela 4).

Analisando os dados da Tabela 4, observase que há influência tanto do meio suporte quanto da macrófita na remoção de CTer.

O estudo de Assunção et al. (2017) mostrou que o uso das macrófitas Eichhornia crassipes e Typha domingensis promoveu, respectivamente, menor e maior variação entre as eficiências de remoção de CTer. Os wetlands construídos com meios suportes de solo+areia e terra, plantados, respectivamente com Typha domingensis, Ceratophyllum demersum (candelabro-aquático), alcançaram eficiências de remoção de CTer superior a 90\%, somente após 30 dias de

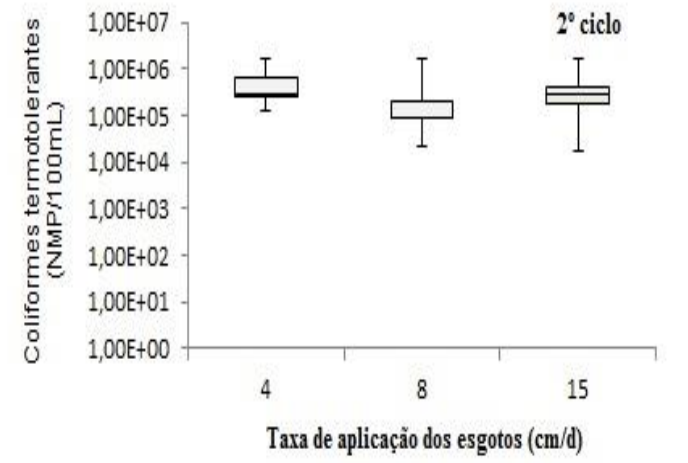

operação. No final do experimento, as eficiências chegaram, respectivamente, a 96,4 e $97,6 \%$, com médias globais de $46,1 \%$ e $76,5 \%$. Este estudo evidencia a influência do tipo de meio suporte e da planta na remoção de CTer. Contudo, nos WCFV com meio suporte de solo, objeto desta pesquisa, não houve necessidade de período de aclimatação para a obtenção de uma eficiência de remoção acima de $90 \%$, e a variação das eficiências de remoção foi menor.

\subsubsection{Influência da colmatação na remoção de CTer}

No $2^{\circ}$ ciclo da cultura do arroz, a maior remoção de CTer dos WCFV que recebeu maior TAH $(15 \mathrm{~cm} / \mathrm{d})$, possivelmente, foi influenciada 
também pela maior colmatação do solo (Figura 5). Esse processo reduz a vazão a ser tratada, mas filtra e remove os microrganismos patogênicos (STEVIK, 2005), aumenta o tempo de detenção hidráulica (TDH) e melhora a distribuição do afluente no leito filtrante (KERAITA et al., 2008). A colmatação também aumenta a probabilidade de adsorção e eliminação, que são os principais mecanismos de imobilização e remoção de CTer em meios porosos (AUSLAND et al., 2002).

Tabela 4: Características e eficiências de remoção de CTer de WCFV avaliados por diferentes autores

\begin{tabular}{|c|c|c|c|c|c|}
\hline Autor & Fluxo & Meio suporte & Planta & $\begin{array}{c}\text { TO } \\
\text { (meses } \\
\text { ) }\end{array}$ & Remoção \\
\hline \multirow{2}{*}{$\begin{array}{l}\text { Amorim et al. } \\
\qquad(2019)\end{array}$} & $V$ & Cascalho $(0,54 \mathrm{~m})$ & $\begin{array}{l}\text { capim Tifton } 85 \\
\text { (Cynodon spp) }\end{array}$ & \multirow[t]{2}{*}{4,7} & 75,0 a $99,0 \%$ \\
\hline & $H$ & Cascalho $(0,60 \mathrm{~m})$ & Taboa (Typha sp.) & & 55,4 a $92,3 \%$ \\
\hline $\begin{array}{l}\text { Avelar, Matos e } \\
\text { Matos (2019) }\end{array}$ & $\mathrm{H}$ & brita no $0(0,20 m)$ & Mentha aquatica & 6 & $\begin{array}{c}1,13 \text { a } 3,46 \\
\text { unidades } \\
\text { logarítmicas }\end{array}$ \\
\hline $\begin{array}{l}\text { Andreo-Martíneza } \\
\text { et al. (2017) }\end{array}$ & $H^{*}$ & $\begin{array}{c}\text { Escória de alto } \\
\text { formo (EAF) + } \\
\text { Areia }\end{array}$ & Phragmites australis & 24 & $53,8 \%$ \\
\hline \multirow{3}{*}{$\begin{array}{l}\text { Assunção et al. } \\
\text { (2017) }\end{array}$} & \multirow{3}{*}{$H^{* * *}$} & $\begin{array}{c}\text { Não teve. Usou } \\
\text { plantas flutuantes }\end{array}$ & $\begin{array}{c}\text { Eichhornia crassipes } \\
\text { (Aguapé) }\end{array}$ & \multirow{3}{*}{3} & $94,6 \%$ \\
\hline & & Terra & $\begin{array}{c}\text { Ceratophyllum } \\
\text { demersum } \\
\text { (candelabro-aquático) }\end{array}$ & & $76,5 \%$ \\
\hline & & $\begin{array}{l}\text { Solo, areia, } \\
\text { pedrisco e brita, na } \\
\text { proporção, } \\
\text { respectivamente, } \\
\text { de } 2: 1: 1: 2\end{array}$ & $\begin{array}{c}\text { Typha domingensis } \\
\text { (Taboa) }\end{array}$ & & $46,1 \%$ \\
\hline $\begin{array}{l}\text { Souza et al. } \\
\quad(2015)\end{array}$ & $V^{* *}$ & Brita & $\begin{array}{c}\text { Copos-de-leite } \\
\text { (Zantedeschia } \\
\text { aethiopica L) }\end{array}$ & 24 & $\begin{array}{c}96 \% \text { com máxima } \\
\text { de } 99,3 \%\end{array}$ \\
\hline $\begin{array}{l}\text { Colares; Sandri } \\
\text { (2013) }\end{array}$ & $\mathrm{H}$ & $\begin{array}{l}\text { Cascalho natural; } \\
\text { Brita } \mathrm{n}^{\circ} 2 \\
\text { Cascalho lavado }\end{array}$ & Typha sp (Taboa) & 8 & $\begin{array}{l}86,28 \% \\
85,03 \% \\
85,75 \%\end{array}$ \\
\hline $\begin{array}{l}\text { Abou-Elela; Hellal } \\
\text { (2012) }\end{array}$ & V & Cascalho & $\begin{array}{c}\text { Canna, Phragmites } \\
\text { australis e papiro de } \\
\text { Chipre }\end{array}$ & 24 & 94 a $99,9 \%$ \\
\hline \multirow{4}{*}{$\begin{array}{c}\text { Almeida e } \\
\text { Almeida (2005) }\end{array}$} & \multirow{4}{*}{$V$} & \multirow{4}{*}{$\begin{array}{c}\text { Brita, areia, casca } \\
\text { de arroz } \\
\text { carbonizada, casca } \\
\text { de coco verde, } \\
\text { seca e substrato } \\
\text { de fibra de côco }\end{array}$} & $\begin{array}{l}\text { Taboa (Typha } \\
\text { angustifólia L.) }\end{array}$ & \multirow{4}{*}{10} & $99,97 \%$ \\
\hline & & & $\begin{array}{l}\text { conta de lágrima (Coix } \\
\text { lacryma-jobi L.) }\end{array}$ & & $99,61 \%$ \\
\hline & & & $\begin{array}{c}\text { Lírio do brejo } \\
\text { (Hedychium } \\
\text { coronarium J. König) }\end{array}$ & & 99,61 \\
\hline & & & $\begin{array}{c}\text { capim } \\
\text { Angola(Urochloa } \\
\text { mutica (Forssk.) T.Q. } \\
\text { Nguyen) }\end{array}$ & & 99,97 \\
\hline
\end{tabular}


Figura 5: Amostra dos solos da camada de $0-10 \mathrm{~cm}$ dos WCFV
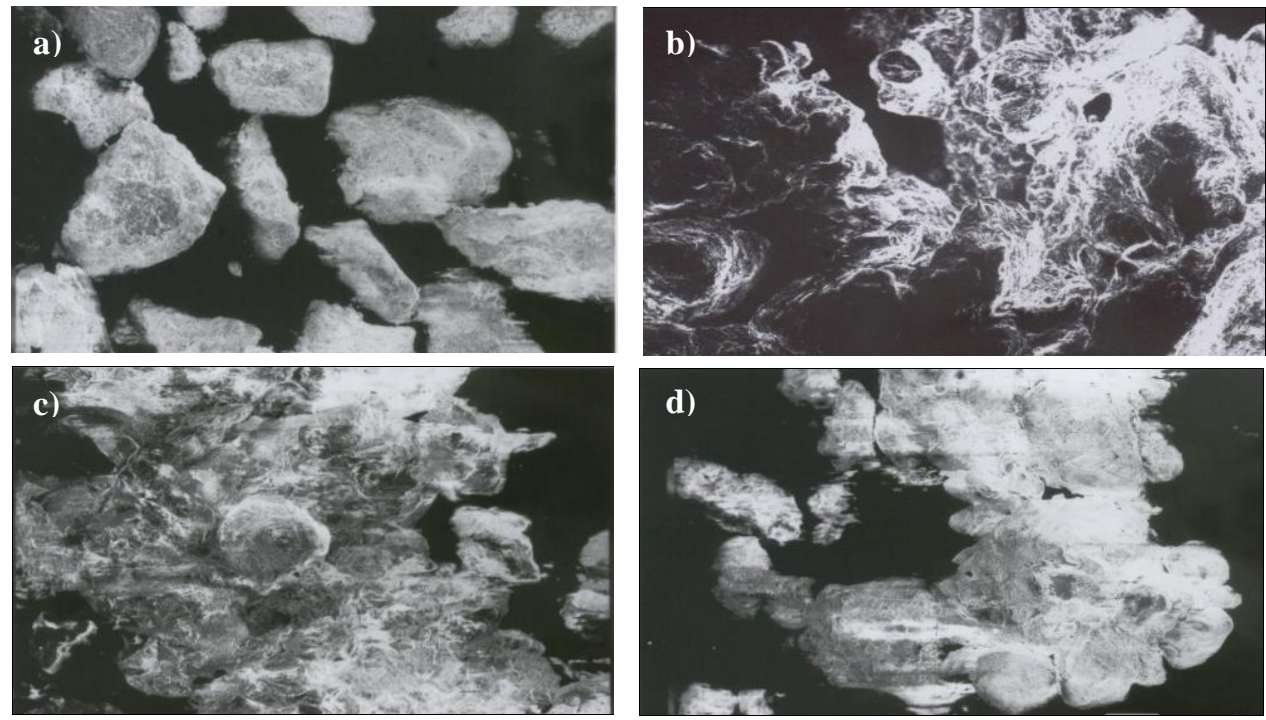

a) antes da aplicação do esgoto; b) final operação com $\mathrm{TAH}=4 \mathrm{~cm} / \mathrm{d}$; c) final operação com $\mathrm{TAH}=8 \mathrm{~cm} / \mathrm{d}$; d) final operação com $\mathrm{TAH}=15 \mathrm{~cm} / \mathrm{d}$. Fonte: Os autores.

Nota-se que os WCFV e CTR operados com maiores TAH $(8$ e $15 \mathrm{~cm} / \mathrm{d})$ apresentaram menores valores de $\mathrm{K}$ e da mesma ordem de grandeza (Tabela 5). Os WCFV e CTR operados com essas TAH, no $2^{\circ}$ ciclo, apresentaram maiores eficiências de remoção de CTer (Tabela 2). Isso leva a concluir que a colmatação tem alguma influência da remoção desses microrganismos. Porém, a baixa umidade dos solos parece favorecer mais a remoção de CTer em relação à colmatação. Logo, é importante controlar o processo de colmatação para manter tanto a vazão a ser tratada como as melhores eficiências de remoção dos CTer.

Tabela 5: Valores médios de condutividade hidráulica (K), dos solos das unidades WCFV operados com diferentes TAH, após o $2^{\circ}$ ciclo da cultura do arroz

\begin{tabular}{ccc}
\hline TAH $(\mathbf{c m} / \mathbf{d})$ & K (cm/s) & CTR \\
\cline { 2 - 3 } & WCFV & $2.35 \times 10^{-4}$ \\
$\mathbf{4}$ & $1,04 \times 10^{-3}$ & $6,10 \times 10^{-5}$ \\
$\mathbf{8}$ & $5,91 \times 10^{-5}$ & $2,63 \times 10^{-5}$ \\
\hline Antes da aplicação do esgoto & $5,85 \times 10^{-5}$ &
\end{tabular}

Fonte: Os autores.

Nota-se que, com o aumento da TAH, houve maior redução da $\mathrm{K}$ dos solos dos WCFV e CTR. $\mathrm{O}$ aumento da TAH levar a valores de $\mathrm{K}$ dos solos (meio suportes) extremamente baixos (LE COUSTUMER et al., 2012), o que causaria o colapso hidráulico do sistema. Assim, recomendase a aplicação de baixas taxas de esgoto e 0 descanso das unidades WCFV e CTR para controlar a colmatação do meio suporte, como também foi observado por Winter e Goetz (2003).

O sistema radicular não contribuiu para a melhoria da $\mathrm{K}$ dos solos (Tabela 5) nos sistemas que receberam TAH de 8 e de $15 \mathrm{~cm} / \mathrm{d}$, pois a $\mathrm{K}$ dos solos plantados (WCFV) e daqueles sem planta (CTR) foi da mesma ordem de grandeza. Logo, o tempo em que o solo levaria para colmatar as camadas internas seria o mesmo, porém, a TAH de $15 \mathrm{~cm} / \mathrm{d}$ causaria uma colmatação mais rápida.

É possível notar diferença entre as raízes da cultura do arroz antes da aplicação do esgoto (Figura 6a) e após o final da operação dos sistemas (Figura 6b, 6c e 6d). O biofilme formado é evidente nas raízes das plantas das unidades WCFV operadas com TAH de $8 \mathrm{~cm} / \mathrm{d}$ (Figura 6b), de $15 \mathrm{~cm} / \mathrm{d}$ (Figura 6c), e nos pelos radiculares daquelas alimentadas com TAH de $4 \mathrm{~cm} / \mathrm{d}$ (Figura $6 d)$. 


\section{Figura 6: Amostra das raízes de arroz dos WCFV}
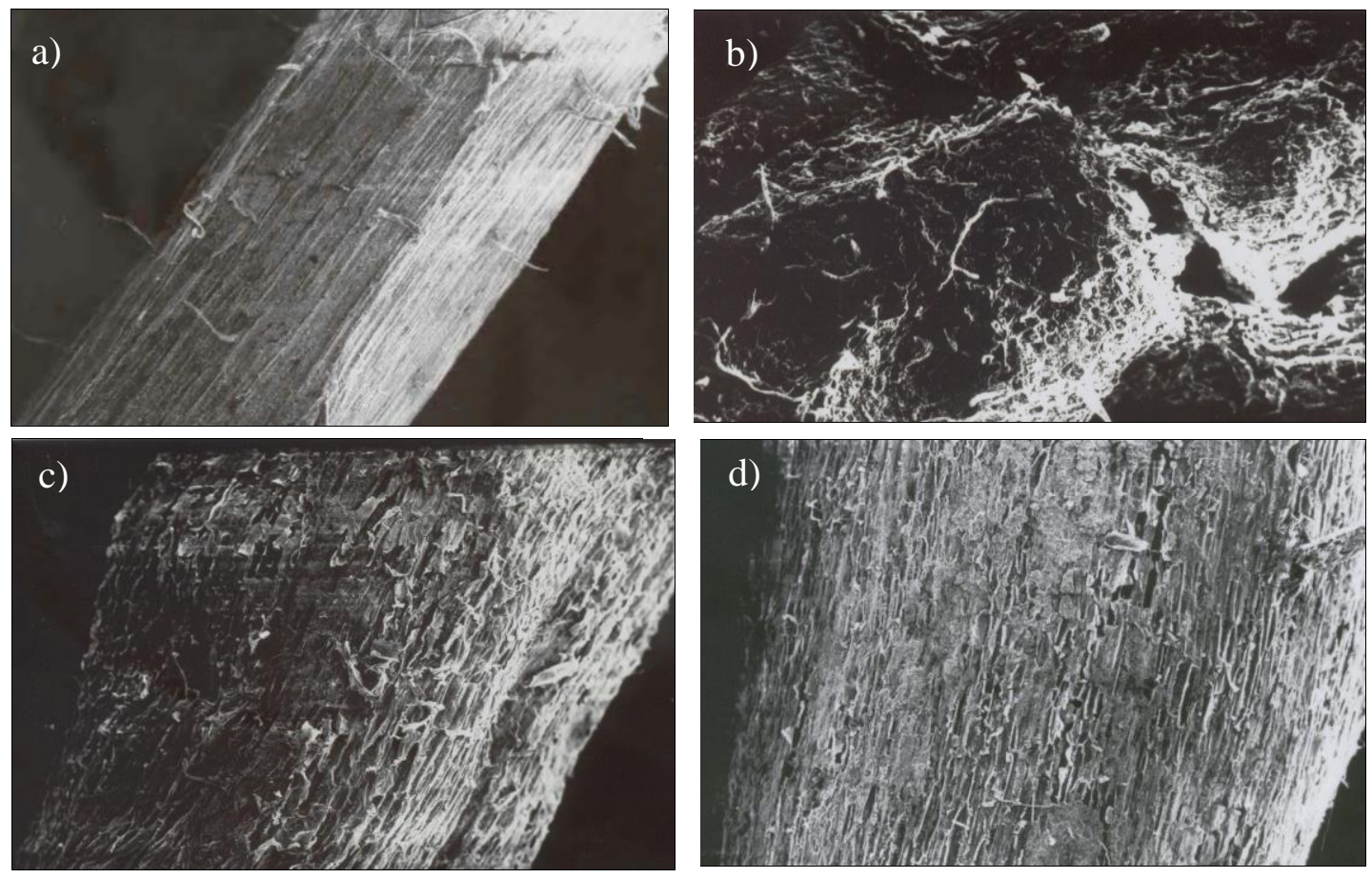

a) antes da aplicação do esgoto; b) final operação com $4 \mathrm{~cm} / \mathrm{d}$; c) final operação com $8 \mathrm{~cm} / \mathrm{d}$; d) final operação com $15 \mathrm{~cm} / \mathrm{d}$. Fonte: Os autores.

\subsection{Sistema de policultura}

\subsubsection{Influência da $T A H$, do tipo de cultura e da $K$ na remoção de CTer}

No sistema 2, de policultura, também foi observada variação na remoção de CTer ao longo do tempo. As concentrações dos afluentes eram da ordem de $2,55 \times 10^{7} \mathrm{NMP} / 100 \mathrm{~mL}$, e efluentes variaram de 0 a $10^{5} \mathrm{NMP} / 100 \mathrm{~mL}$.

No $1^{\circ}$ ciclo, mesmo com os solos (Latossolo Amarelo) de todas as unidades tendo sido plantados somente com a cultura do arroz, as eficiências de remoção de CTer foram inferiores (Tabela 6) àquelas obtidas com o Latossolo Vermelho-Amarelo (Tabela 2). Essa redução da eficiência de remoção, possivelmente, ocorreu devido ao Latossolo Amarelo ser mais arenoso e possuir maior $\mathrm{K}$.

No $2^{\circ}$ ciclo, foi observado um leve aumento nas eficiências de remoção de CTer, independente do tipo de cultura, sendo maior quando se aplicou a TAH de $2,4 \mathrm{~cm} / \mathrm{d}$ de esgoto para tratamento. Durante o $3^{\circ}$ e $\circ 4^{\circ}$ ciclo, as eficiências reduziram, porém, no $3^{0}$ ciclo foram maiores quando a TAH foi de $2,4 \mathrm{~cm} / \mathrm{d}$. No $4^{\circ}$ ciclo, a remoção foi maior nas unidades operadas com $4,7 \mathrm{~cm} / \mathrm{d}$ (Tabela 7). Isso, possivelmente, ocorreu em função da colmatação do solo (Tabela 8), que contribuiu para a remoção dos microrganismos patogênicos.

A influência das culturas na remoção de CTer dos esgotos afluentes não foi observada.

A $\mathrm{K}$ dos solos antes da aplicação do esgoto era de $4,58 \times 10^{-2} \mathrm{~cm} / \mathrm{s}$, e se manteve na mesma ordem de grandeza até o $3^{\circ}$ ciclo, independente da TAH. No $4^{\circ}$ ciclo, as $\mathrm{K}$ dos solos das unidades que receberam $\mathrm{TAH}$ de $2,4 \mathrm{~cm} / \mathrm{d}$ aumentaram. Isso, possivelmente, ocorreu devido à aplicação de baixas $\mathrm{TAH}$, à rotação de culturas e ao descanso do solo antes da medida da perda de carga final. A redução da $K$ nas unidades operadas com $4,7 \mathrm{~cm} / \mathrm{d}$ pode ser explicada pela maior $\mathrm{TAH}$, que favoreceu maior colmatação dos solos (Tabela 8).

Assim, a forma de operação associada aos parâmetros de projeto e a escolha adequada da planta são, portanto, elementos-chave no projeto, pois podem limitar a colmatação e, consequentemente, aumentar indiretamente a carga anual tratada (LE COUSTUMER et al., 2012) e manter uma eficiência de remoção de CTer desejada. A remoção de microrganismos patogênicos em wetlands construídos parece ser um processo complexo, pode variar ao longo do tempo e depende de muitos fatores, porém, o meio suporte de granulometria mais fina influencia significativamente a remoção de CTer (MORATÓ et al., 2014). 
Tabela 6: Concentrações médias (NMP/100 ml) e eficiência de remoção (\%) de CTer dos WCFV plantados com a cultura do arroz, no $1^{\circ}$ ciclo de operação

\begin{tabular}{ccc}
\hline TAH (cm/d) & NMP/100 $\mathbf{~ m l}$ & $\%$ \\
\hline $\mathbf{2 , 4}$ & $3,40 \times 10^{4}$ & 99,8669 \\
$\mathbf{4 , 7}$ & $6,27 \times 10^{4}$ & 99,7545 \\
\hline
\end{tabular}

Fonte: Os autores.

Tabela 7: Concentrações médias (NMP/100 ml) e eficiência de remoção (\%) de CTer dos WCFV plantados com diferentes culturas no $2^{\circ}$ ao $4^{\circ}$ ciclos

\begin{tabular}{cccccccc}
\hline \multirow{2}{*}{$\begin{array}{c}\text { TAH } \\
\text { (cm/d) }\end{array}$} & \multirow{2}{*}{ Cultura } & \multicolumn{2}{c}{$\mathbf{2}^{\mathbf{0}}$ ciclo } & \multicolumn{2}{c}{$\mathbf{3}^{\mathbf{0}}$ ciclo } & \multicolumn{2}{c}{$\mathbf{4}^{\mathbf{0}}$ ciclo } \\
\cline { 2 - 8 } & & $\mathbf{N M P} / \mathbf{1 0 0} \mathbf{~ m l}$ & \% & NMP/100 $\mathbf{~ m}$ & $\%$ & NMP/100 $\mathbf{~} \mathbf{~}$ & $\%$ \\
\hline \multirow{2}{*}{$\mathbf{2 , 4}$} & $\mathbf{A}$ & $2,00 \times 10^{1}$ & $\mathbf{9 9 , 9 9 9 9}$ & $8,50 \times 10^{3}$ & 99,9667 & $5,60 \times 10^{5}$ & 97,8070 \\
& $\mathbf{F}$ & $4,00 \times 10^{2}$ & $\mathbf{9 9 , 9 9 8 4}$ & $2,10 \times 10^{4}$ & 99,9178 & $2,90 \times 10^{4}$ & 99,8864 \\
& $\mathbf{M}$ & $1,00 \times 10^{1}$ & $\mathbf{1 0 0 , 0 0 0 0}$ & $1,10 \times 10^{4}$ & 99,9569 & $6,40 \times 10^{5}$ & 97,4937 \\
\hline \multirow{2}{*}{$\mathbf{4 , 7}$} & $\mathbf{A}$ & $2,50 \times 10^{4}$ & 99,9021 & $6,10 \times 10^{4}$ & 99,7611 & $6,00 \times 10^{4}$ & 99,7650 \\
& $\mathbf{F}$ & $5,00 \times 10^{2}$ & 99,9980 & $8,20 \times 10^{4}$ & 99,6789 & $3,20 \times 10^{4}$ & 99,8747 \\
& $\mathbf{M}$ & $4,00 \times 10^{4}$ & 99,8434 & $7,60 \times 10^{5}$ & 97,0238 & $1,60 \times 10^{3}$ & 99,9937 \\
\hline
\end{tabular}

Obs: A - Arroz, F - Feijão e M - Milho. Fonte: Os autores.

Tabela 8: $\mathrm{K}(\mathrm{cm} / \mathrm{s})$ média dos solos dos WCFV plantados com diferentes culturas

\begin{tabular}{|c|c|c|c|}
\hline $\mathrm{TAH}(\mathrm{cm} / \mathrm{d})$ & $1^{\circ}$ ciclo & $3^{\circ}$ ciclo & $4^{\circ}$ ciclo \\
\hline 2,4 & $2,31 \times 10^{-2}$ & $4,74 \times 10^{-2}$ & $2,03 \times 10^{-1}$ \\
\hline 4,7 & $4,58 \times 10^{-2}$ & $3,20 \times 10^{-2}$ & $2,91 \times 10^{-3}$ \\
\hline & aplicação c & & $4,58 \times 10^{-2}$ \\
\hline
\end{tabular}

Fonte: os autores.

\section{CONCLUSÃO}

Os resultados obtidos permitem concluir que a operação em fluxo não saturado, a intermitência e a colmatação contribuíram para a remoção dos CTer, sendo os dois primeiros os fatores que mais influenciaram no processo, uma vez que promoveram a redução da umidade do solo e a decomposição mais rápida da matéria orgânica. Os dois tipos de solos (Latossolo vermelhoAmarelo e Latossolo Amarelo) apresentaram eficiência semelhantes, com o Latossolo Amarelo sendo mais favorável ao controle da colmatação.

Independente do tipo de solo e dele estar sendo cultivado com monocultura ou policultura, no início de operação dos sistemas, as TAH mais baixa favoreceram uma maior remoção de CTer com maior variabilidade nas eficiências. Após cinco meses, as eficiências de remoção se tornaram aproximadamente constantes e foram melhores quando se utilizou maiores TAH. A rotação de culturas melhorou tanto 0 desempenho dos WCFV na remoção de CTer quanto controlou a colmatação do solo, mantendo a vazão a ser tratada.

Para que se possa estabelecer parâmetros de projetos adequados para wetlands construídos que tenham objetivos de remover CTer com eficiências aproximadamente constantes, para o período de projeto desejado, é importante que as pesquisas continuem. Recomenda-se a utilização de qualquer dos dois tipos de solo modificado, desde que mantenha uma $\mathrm{K}$ acima de $10^{-3} \mathrm{~cm} / \mathrm{s}$, a rotação de culturas e, também, um maior intervalo entre as aplicações dos esgotos para tratamento quando se utilizar maiores $\mathrm{TAH}$.

\section{AGRADECIMENTOS}

Os autores gostariam de agradecer ao $\mathrm{CNPq}-$ Conselho Nacional de desenvolvimento científico e tecnológico e a FAPESB - Fundação de Amparo à Pesquisa do Estado da Bahia pelo financiamento das pesquisas.

\section{REFERÊNCIAS}

ABEL, C. D. T.; SHARMA, S. K.; MERSHA, S. A.;

KENNEDY, M. D. Influence of intermittent infiltration of 
primary effluent on removal of suspended solids, bulk organic matter, nitrogen and pathogens indicators in a simulated managed aquifer recharge system.

Ecological Engineering, v. 64, p.100-107, 2014. https://doi:10.1016/j.ecoleng.2013.12.045.

ABOU-ELELA, S. I.; HELLAL, M. S. Municipal wastewater treatment using vertical flow constructed wetlands planted with Canna, Phragmites and Cyprus. Ecological Engineering, v. 47, p. 209-213, 2012. https://doi.org/10.1016/j.ecoleng.2012.06.044.

ALBERTS, B.; BRAY, D.; LEWIS, J.; RAFF, M.; ROBERTS, K.; WATSON, J. D. Biologia molecular da célula. Tradução. Amauri Braga Simonetti [et al]. 3. ed. Porto Alegre: Ed. Artes Médicas, 1997. p. 146-152.

ALMEIDA, R.A.; ALMEIDA, N.A.M. Remoção de coliformes do esgoto por meio de espécies vegetais. Revista Eletrônica de Enfermagem, v. 7, n. 3, p. 306317, 2005.

AMORIM, F.; MOTA, J. R.; FIA, R.; OLIVEIRA, L. F. C.; CAMPOS, C. M. M. Coliform removal in a constructed wetland system used in post-swine effluent treatment. Revista Ambiente e Água, Taubaté, v. 14 n. 5, e 2402, 2019. https://doi:10.4136/ambi-agua.2402.

ANDRAUS, S. Aspectos Sanitários das Águas do Mar e Areias das Praias de Matinhos, Caiobá e Guaratuba - PR. Dissertação (Mestrado em Ciência do Solo), Departamento de Solos e Engenharia Agrícola, Universidade Federal do Paraná, Curitiba, 2006.

ANDREO-MARTÍNEZA, P.; GARCÍA-MARTÍNEZ, N.; QUESADA-MEDINA, J.; ALMELA, L. Domestic wastewaters reuse reclaimed by an improved horizontal subsurface-flow constructed wetland: a case study in the southeast of Spain, Bioresource Technology, v. 233, p. 236-246, 2017.

http://dx.doi.org/10.1016/j.biortech.2017.02.123.

APHA-AWWA-WPCF. Standard Methods for the Examination of Water and Wastewater. 16th edition. American Public Health Association, Washington, DC, 1985. 1268p.

ASSUNÇÃO, A. W. A.; GATTI JUNIOR, P. G.; ALMEIDA, R. V.; GASPAROTTO, Y.; AMARAL, L. A. Utilização de macrófitas aquáticas de três diferentes tipos ecológicos para remoção de Escherichia coli de efluentes de criação de pacu. Engenharia Sanitária e Ambiental, v. 22, n. 4, p.657-663, 2017. https://doi:10.1590/S1413-41522017144278.

AUSLAND, G.; STEVIK, T. K.; HANSSEN, J.F.; KHLER, J. C.; JENSSEN, P. D. Intermittent filtration of wastewater-removal of fecal coliforms and fecal streptococci. Water Reserch, v. 36, n. 14, p. 35073516, 2002. https://doi.org/10.1016/S00431354(02)00060-X.
AVELAR, F.; MATOS, A. T. de; MATOS, M. P. de. Remoção de contaminantes do esgoto sanitário em sistemas alagados construídos cultivados com Mentha aquática. Engenharia Sanitária e Ambiental, Rio de Janeiro, v. 24, n. 6, p.1259-1266, 2019. https://doi.org/10.1590/s1413-41522019116019.

BLAZEJEWSKI, R.; MURAT-BLAZEJEWSKA, S. Soil clogging phenomena in constructed wetlands with subsurface flow. Water Science and Techology, v. 35, n. 5. p. 183-188, 1997. https://doi.org/10.1016/S02731223(97)00067-X.

CAVINATTO, A. S.; PAGANINI, W. S. Os microrganismos nas atividades de disposição de esgotos no solo - estudo de caso. Revista Engenharia Sanitária e Ambiental, v.12, n. 1, p. 42-51, 2007, https://doi.org/10.1590/S1413-41522007000100006.

COLARES, C. J. G.; SANDRI, D. Eficiência do tratamento de esgoto com tanques sépticos seguidos de leitos cultivados com diferentes meios de suporte. Revista Ambiente \& Água, v. 8, n.1, p.172-185, 2013. https://doi.org/10.4136/ambi-agua.1047.

FORTES NETO, P.; FORTES, N. C. P.; SILVA, E. M. A. M; BRAMBATTI, F. Interaction between Thermotolerant Coliforms and Rhizobacteria in Soil Fertilized with Treated Domestic Wastewater. Revista Brasileira de Ciência do Solo, Viçosa, v. 41, e0160109, 2017. https://doi.org/10.1590/18069657rbcs20160109.

FU, G.; ZHANG, J.; CHEN, W.; CHEN, Z. Medium clogging and the dynamics of organic matter accumulation in constructed wetlands. Ecological Engineering, Amsterdam, v. 60, p. 393-398, 2013. https://doi.org/10.1016/j.ecoleng.2013.09.012.

HORN, R.; SMUCKER. A. Structure formation and its consequences for gas and water transport in unsaturated arable and forest soils. Soil and Tillage Research, v. 82, n. 1, p. 5-14, 2005. https://doi.org/10.1016/j.still.2005.01.002.

KERAITA, B.; DRECHSEL, P.; KONRADSEN, F.; VREUGDENHIL, R. C. Potential of simple filters to improve microbial quality of irrigation water used in urban vegetable farming in Ghana. Journal of Environmental Science and Health, Part A: Toxic/Hazardous Substances and Environmental Engineering, v. 43, n. 7, p. 749-755, 2008. https://doi:10.1080/10934520801959948

LE COUSTUMER, S.; FLETCHER, T. D.; DELETIC, A.; BARRAUD, S.; POELSMA. P. The influence of design parameters on clogging of stormwater biofilters: a largescale column study. Water Research, v. 46, n. 20, p. 6743-6752, 2012. https://doi:10.1016/j.watres.2012.01.026.

MAGESAN, G. N.; WILLIAMSON, J. C.; YEATES, G. W.; LLOYD-HONES, A. Rh. Wastewater C:N ratio 
effects on soil hydraulic conductivity and potential mechanisms for recovery. Bioresource Technology, v. 71, n. 1, p. 21-27, 2000. https://doi.org/10.1016/S09608524(99)00054-1.

MATOS, M. P. de; von SPERLING M.; MATOS, A. T.; PASSOS, R. G. Uso de traçador salino para avaliação da colmatação e das condições hidrodinâmicas em sistemas alagados construídos de escoamento horizontal subsuperficial. Journal of the Brazilian Association of Agricultural Engineering, v. 35, n. 6, p.1137-1148, 2015. :http://dx.doi.org/10.1590/18094430-Eng.Agric.v35n6p1137-1148/2015.

; DIAS, D. F

C.; SANTOS, C. R. S. Colmatação e desempenho de sistemas alagados construídos de escoamento horizontal subsuperficial ao longo de oito anos de operação. Engenharia Sanitária e Ambiental, Rio de Janeiro, v. 23, n. 06, p.1227-1237, 2018. https://doi.org/10.1590/s1413-41522018175770.

MORATÓ, J.; CODONY, F.; SÁNCHEZ, O.; PÉREZ, L. M.; GARCÍA, J.; MAS, J. Key design factors affecting microbial community composition and pathogenic organism removal in horizontal subsurface flow constructed wetlands. Science of The Total Environment, v. 481, p. 81-89, 2014. http://doi:10.1016/j.scitotenv.2014.01.068.

SILVA, S. C.; BERNARDES, R. S.; RAMOS, M. L. G. Remoção de matéria orgânica do esgoto em solo de wetland construído. Revista Engenharia Sanitária e Ambiental, v. 20, n. 4, p. 533-542, 2015. http://doi: 10.1590/S1413-41522015020040075357.

SILVA, N.; JUNQUEIRA, V. C. A.; SILVEIRA, N. F. A.; TANIWAKI, M.H.; SANTOS, R.F.S.; GOMES, R.A.R. Manual de métodos de análise microbiológica de alimentos. 4. ed. São Paulo: Livraria Varella, 2010. $624 \mathrm{p}$.
SOUZA, C. F.; BASTOS, R. G.; GOMES, M. P. M.; PULSCHEN, A. A. Eficiência de estação de tratamento de esgoto doméstico visando reuso agrícola. Revista Ambiente \& Água, v. 10, n. 3, p. 587-597, 2015. http://dx.doi.org/10.4136/ambi-agua.1549.

STEFANAKIS, A. I.; AKRATOS, C. S. Removal of pathogenic bacteria in constructed wetlands: mechanisms and efficiency, In book: Phytoremediation - Management of Environmental Contaminants, Springer International Publishing, v. 4, p.327-346, 2016. https://doi: 10.1007/978-3-319-41811-7_17.

STEVIK, T. K.; KARI, A.; AUSLAND, G.; JENSSEN, P. $D$. Retention and removal of pathogenic bacteria in wastewater percolating through porous media: a review. Water Research. v. 38, p. 1355-1367, 2004. https://doi.org/10.1016/j.watres.2003.12.024.

TREIN, C. M; PELISSARI, C.; HOFFMANN, H.; PLATZER, C.J.; SEZERINO, P. H. Tratamento descentralizado de esgotos de empreendimentos comercial e residencial empregando a ecotecnologia dos wetlands construídos. Revista Ambiente Construído, v. 15, n. 4, p.351-367, 2015. https://doi.org/10.1590/s1678-86212015000400055.

von SPERLING, M. Introdução à qualidade das águas e ao tratamento dos esgotos. 4. ed. Belo Horizonte: UFMG, 2014. V. 1, 472p.

WINTER, K. J; GOETZ, D. The impact of sewage composition on the soil clogging phenomena of vertical flow constructed wetlands. Water Science and Technology, v. 48, n. 5, p. 9-14, 2003. https://doi:10.2166/wst.2003.0268.

VYMAZAL, J. Constructed wetlands for wastewater treatment: five decades of experience. Environmental. Science and Technology, v. 45, n.1, p. 61-69, 2011. https://doi.org/10.1021/es101403q 